\title{
A STUdy ON THE DEVELOPMENTAL CHANGE IN THE INTERPRETATION OF INDETERMINATE NUMBER WORDS
}

\author{
Tsukiharu KUMAE
}

Hiroshima University

Suppose that two persons judge independently of the quality of any one thing. Here arises a question. Is the difference in the judgement expressed there due to the difference of their interpretation of the words? For example, one person says "It s good", and the other says "It is very good". But what difference is meant by these two persons in saying "good" and "very good"? It can be that "good" for a person is equal in the meaning to "very good" for another person. Indeed, indeterminate number words such as "very", "fairly" and "many" etc. are frequently used in the daily life situations, the meanings, however, are not necessarily clear; that is, the degrees or quantities meant by those words differ greatly according to the person or to the situation. Sheppard says: "Admittedly such quantitative terms may be imprecise in meaning, yet it is generally considered that there will be fair agreement in the interpretation of these terms, provided that the quality which is being described is well known (5, p. 40)." In fact, I have the data that there is a great difference in the interpretation of, for example, "many" between adults and preschool children even under the same situation, because as compared with adults, preschool children are narrow in experience resulting in the poorer determinate number concept (or simply, number concept).

At the same time, I wrote elsewhere that in preschool children, who generally grow and develop repidly, the quantity for "many" tended to increase with age $(2,3)$. This fact was never made clear up to recent time because of the lack of an appropriate method for determining the meaning with preschool children.

The operational method is one developed by Cohen et al. (1) and Kumae $(2,3,4)$ independently. In this method a subject is requested to take out "many of" or "a few of" etc. beads from a container and put them on a tray. The actual number taken is regarded as the score. As this method is available even to four year old children, we can easily see how the interpretation of indeterminate number words varys with ages of preschool children through adults using one and the same method. Thus, this study investigates the developmental change in the interpretation of such indeterminate number words.

Method

Materials: Containers, trays and beads were used for this experiment. Containers were 12 in all and they were all the same in size and color. But they were different in that they contained a different number (background number) or beads; that is, four of them held 100 beads respectively, the next four held 200 beads respectively, and each of the last four held 300 beads. Thus three background numbers $(100,200,300)$ were prepared for each word. The beads were thin and were $1.5 \mathrm{~cm}$ in diameter. The containers were put on the table one at a time, and the tray in which beads were to be put was placed beside the container.

Stimulus words: Stimulus words were "very many of", "many of", "a few of" and "a very few of". Besides these four words, another word was prepared but has been eliminated here because of the lack of an appropriate English equivalent.

Subjects: The subjects consisted of 30 preschool children aged 6 years, 40 school children aged 8 years and 40 school children aged 11 years in Hiroshima City.

Procedure: The children were tested individually. Each child sat down on a chair before a table. He was asked to take out, for example, "many of" beads from a container and put them in a tray. This procedure was followed with each of the other three stimulus words. Needless to say, the meaning of each stimulus word was determined under three conditions depending on the background number.

\section{Results and Discussion}

Table 1 presents the means and standard deviations of the scores for four stimulus words under three background numbers.

It apparently shows that the scores of preschool children are, without exception, lower than those of

The author is indebted to Dr. I. Koura of Hiroshima University for his valuable advice and encouragement during all phases of this study. 
school children. And as to two groups of school children it can be said that there is no difference in the scores. under any condition of the background number.

Table 1

\begin{tabular}{l|r|rrrrrr}
\hline \multirow{2}{*}{ Stimulus word } & \multirow{2}{*}{ Age } & \multicolumn{2}{|c}{100} & \multicolumn{2}{c}{200} & \multicolumn{2}{c}{300} \\
& & Mean & SD & Mean & SD & Mean & SD \\
\hline \multirow{3}{*}{ Very many of } & 6 & 23.6 & 10.8 & 29.0 & 14.2 & 32.3 & 17.1 \\
& 8 & 68.5 & 11.1 & 158.8 & 20.5 & 217.8 & 19.0 \\
& 11 & 67.0 & 7.8 & 149.9 & 14.5 & 235.8 & 17.8 \\
\hline \multirow{3}{*}{ Many of } & 6 & 22.1 & 9.8 & 25.2 & 12.0 & 28.4 & 16.2 \\
& 8 & 62.0 & 14.6 & 140.8 & 22.1 & 196.6 & 25.2 \\
& 11 & 60.6 & 7.1 & 131.1 & 17.7 & 199.8 & 23.5 \\
\hline \multirow{3}{*}{ A few of } & 6 & 5.9 & 6.8 & 8.1 & 4.6 & 9.1 & 5.3 \\
& 8 & 17.3 & 5.8 & 33.8 & 14.1 & 55.7 & 12.5 \\
& 11 & 22.4 & 7.2 & 41.4 & 10.0 & 60.1 & 15.3 \\
\hline \multirow{3}{*}{ A very few of } & 8 & 15.1 & 5.5 & 29.3 & 13.2 & 45.2 & 10.9 \\
& 11 & 14.9 & 5.0 & 31.4 & 10.6 & 41.7 & 13.0 \\
\hline
\end{tabular}

As for the scores for "very many of" and "many of" these results could be expected from my previous study in which the subjects consisted of preschool children aged 4, 5 and 6 years from a kindergarten $(2,3)$. In that study the author pointed out that scores, particularly of "very many of" and "many of" tended to increase with age, suggesting a close relationship between the development of a determinate number concept and that of an indeterminate number concept. In fact, it is generally recognized that preschool children tend to use the word "many" for the number which exceed the limit of his determinate number concept; for example, an young boy can count one, two, three, etc., but he says "many" for six, because six is the number which exceed the scope of his determinate number concept. The above, however, can be appropriate to the preschool children only, and not to the school children or to the feeble-minded. As the preschool children are very poor in a determinate number concept, it may be reasonable to consider that such children regard a smaller number of beads as many whereas the school children regard a larger number as many. Therefore, the marked difference between the scores of preschool and school children seems to be natural. And the fact that there is no significant difference between the scores of two groups of school children shows that they understand these words almost equally.

Another problem to be taken up is concerned with the scores for "a few of" and "a very few of". In this instance too, there is a marked difference between the scores of preschool and school children. I suppose it is concerned with the above statement of the development of determinate and indeterminate number concept. Although the scores increased, and therefore, the increment in the scores for these two words may generally be observed among the ages in this study, that will not be the case in the older children or in the adults, whose scores may rather decrease. It cannot be considered at all in the cases of "a few of" and "a very few of" that the scores always increase with age. The analysis of the data using older children and adults as subjects may suggest some important information as to the present interpretation or discussion of this point.

A mention should be made here of the differentiation of the meaning. As I refered to elsewhere (3), by differentiation is meant gradual discrimination between the meanings of the words with age. In other words, it means that the difference between the four scores under the same background number becomes greater with age. It must be emphasized that presupposing this differentiation, all the scores increase with age. For example, although the scores of school children for "a few of" and "a very few of" are greater than those of preschool children, the difference between the highest and the lowest scores is greater in school children than in preschool children. This result is the very point contradictory to Cohen et al.'s one. Although I 
cannot properly answer the reason why two studies contradicted each other, it is difficult for me to regard his result as differenti tion.

The last problem I have to take up is the effect of the increment of the background number on scores. It is quite natural that scores increase according to the increment of the background number. But how do they increase? In order to answer this question, the ratio of the number taken compared with the background number was computed in all cases and graphed in Fig. 1,2 and 3. As seen in the figures, the values for "very many of" and "many of" show rising tendencies in the school children, but decline rapidly in the preschool children when expressed as percentage of the background number. The scores of "a few of" and "a very few of" in school children come to be twofold and threefold on the whole corresponding to the increment of the background number, but this was not the case in preschool children.

\section{Summary}

This study aims to see a developmental change in the interpretation of indeterminate number words. Three groups of 30 preschool children aged 6 years, 40 school children aged 8 years and 40 school children aged 11 years were used as the subjects. Stimulus words selected for this test were "very many of", "many of", "a few of" and "a very few of".

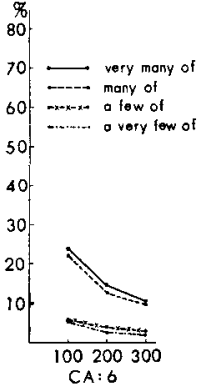

Fig. 1

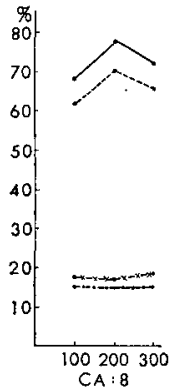

Fig. 2

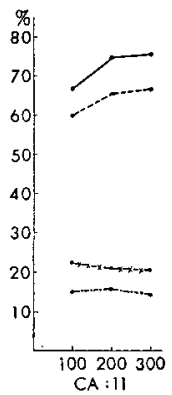

Fig. 3

From the fact presented in Table 1 that there is a marked difference between the scores of preschool children and those of school children, it was made clear that when preschool and school children use the indeterminate number words in their daily life situations, the quantities meant by preschool children differ greatly from those by school children, and at the same time a close relationship between the development of a determinate number concept and that of an indeterminate number concept was suggested. The fact that there is no significant difference between the scores of two groups of school children shows that they understand these words almost equally. In this study too, there was found gradual discrimination between the meanings of the words with age. The author takes the view that differentiation was found here.

Last problem is how do scores increase according to the increment of the background number. Fig. 1, 2 and 3 answer this question. As recognized from the curves for school children, the scores of "a few of" and "a very few of" come to be twofold and threefold on the whole corresponding to the increment of the background number. The curves for "very many of" and "many of" show rising tendencies. In the case of 6 years of age, on the contrary, all curves decline rapidly.

\section{REFERENCES}

1. Cohen, J., Dearnley, E. J., \& Hansel, C.E.N.A A quantitative study of meaning. Brit. J. educ. Psychol., 1958, 28, 144-148.

2. Kumae, $T$. The measurement of meaning of indeterminate number word in preschool children: 1. Jap. J. of educ. Psychol., 1960, 8, 106-111.

3. Kumae, T. An operational determination of the meaning of quantitative words inpreschool children. Jap. Psychol. Res. 1960, 2, 106-110.

4. Kumae, $T$. The meaning of indeterminate number words in feeble-minded children. Jap. J. Psychol., 1962, 32, 347-352.

5. Sheppard, D. The adequacy of everyday quantitative expressions as measurements of qualities. Brit. J. Psychol., 1954, 45, 40-50.

MS. received VII 26 ' 62.

Tsukiharu Kumae (隈江月晴 1930- ) 1953 B.A., 1958 M.A.; 1960- Assistant, Hiroshima University. 